\title{
Primary Pulmonary Mucinous (Colloid) Adenocarcinoma that Arose in the Cavernomyoplasty Area in a Patient with Tuberculosis: A Rare Case Report
}

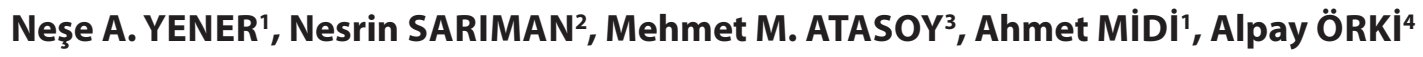 \\ Department of ${ }^{1}$ Pathology, ${ }^{2}$ Chest Disease, ${ }^{3}$ Radiology and ${ }^{4}$ Chest Surgery, Maltepe University, Faculty of Medicine, iSTANBUL, TURKEY
}

\section{ABSTRACT}

Primary pulmonary mucinous (colloid) adenocarcinoma is a rare type of lung cancer. Its arising in the cavernomyoplasty area has not been reported before. We here describe a sixty-year-old man with a previous history of multidrug-resistant and surgically-treated tuberculosis who was diagnosed as primary mucinous adenocarcinoma in the cavernomyoplasty site. We discuss the relevant literature on this rare entity.

Key Words: Lung neoplasms, Mucinous adenocarcinoma, Tuberculosis

\section{INTRODUCTION}

Primary pulmonary mucinous (colloid) adenocarcinoma is a rare type of lung cancer with distinct histopathological features $(1,2)$. Its arising in the lung areas adjacent to the tuberculosis sequela $(3,4)$ or its arising in patients with history of thoracoplasty (5) was reported in the literature. However, its occurrence in the cavernomyoplasty site has not been reported before. We here describe a sixty-yearold man with a previous history of multidrug-resistant and surgically-treated tuberculosis who has got primary pulmonary mucinous adenocarcinoma that arose in the cavernomyoplasty site. We discuss the relevant literature on this rare entity.

\section{CASE REPORT}

A sixty-year-old man applied to our emergency service with one-month history of cough, fever and weight loss. He has got eight-pack-year history of smoking and stopped smoking ten years ago. His past medical history revealed that he had been treated for multidrug-resistant tuberculosis 30 years prior. Ten years after this, he applied to the emergency service with massive hemoptysis. Due to his insufficient cardiopulmonary reserve resulted from extensive tuberculosis sequela, he didn't undergo anatomic resection for the cavities but cavernomyoplasty to control his hemoptysis. He continued to come for follow-up for many years since his last referral to our hospital for left-sided empyema. Sputum smear and pleural fluid was microbiologically negative for tuberculosis bacilli.

(Turk Patoloji Derg 2017, 33:62-65)

Received : 09.10.2012 Accepted : 02.12.2012
Radiologically, the X-ray image revealed increased pulmonary opacities and patchy consolidation of the left lung (Figure 1A). CT scan and PET-CT fusion images showed cavitations in the left lung (Figure 1B,C). These were thick-walled cavitary mass lesions with air-fluid level. There were also traction bronchiectasis, pleural and parenchymal fibrotic changes that resulted in lung volume depletion, highly suggestive findings for tuberculosis sequela in both lungs (Figure 1B).

Then, the patient was undertaken video-assisted thoracoscopy with the presumptive diagnosis of empyema. Extensive debridement of the diffuse cavitary lesions of the left lung was made. Grossly, the material was totally gelatinous (Figure 2). Microscopically, it was an invasive tumor composed of large pools of mucin with sparse neoplastic cells floating within the mucin pools (Figure 3). These cells were in goblet cell morphology in some areas whereas they were in signet ring cell morphology in others. Immunohistochemically, they were strongly positive for CK20, CEA and MUC2 (Figure 4A-C) and negative for CDX2 (Figure 4D), CK7 and TTF-1. The large mucin pools of the tumor stained positively for CEA and MUC5AC (Figure 4E). Then, the specimen was entirely submitted to show any granulomatous inflammation. There wasn't any sign of granulomatous inflammation or tuberculosis bacilli with Ziehl-Neelsen stain. The diagnosis of mucinous adenocarcinoma (colloid carcinoma) was made. The case was accepted as primary lung cancer after a careful systemic investigation including CT, PET scan and colonoscopy

Correspondence: Neșe A. YENER

Maltepe Üniversitesi, Tip Fakültesi, Patoloji Anabilim Dalı,

İSTANBUL, TURKEY

E-mail: nese.yener@maltepe.edu.tr Phone: +90 5053898454 

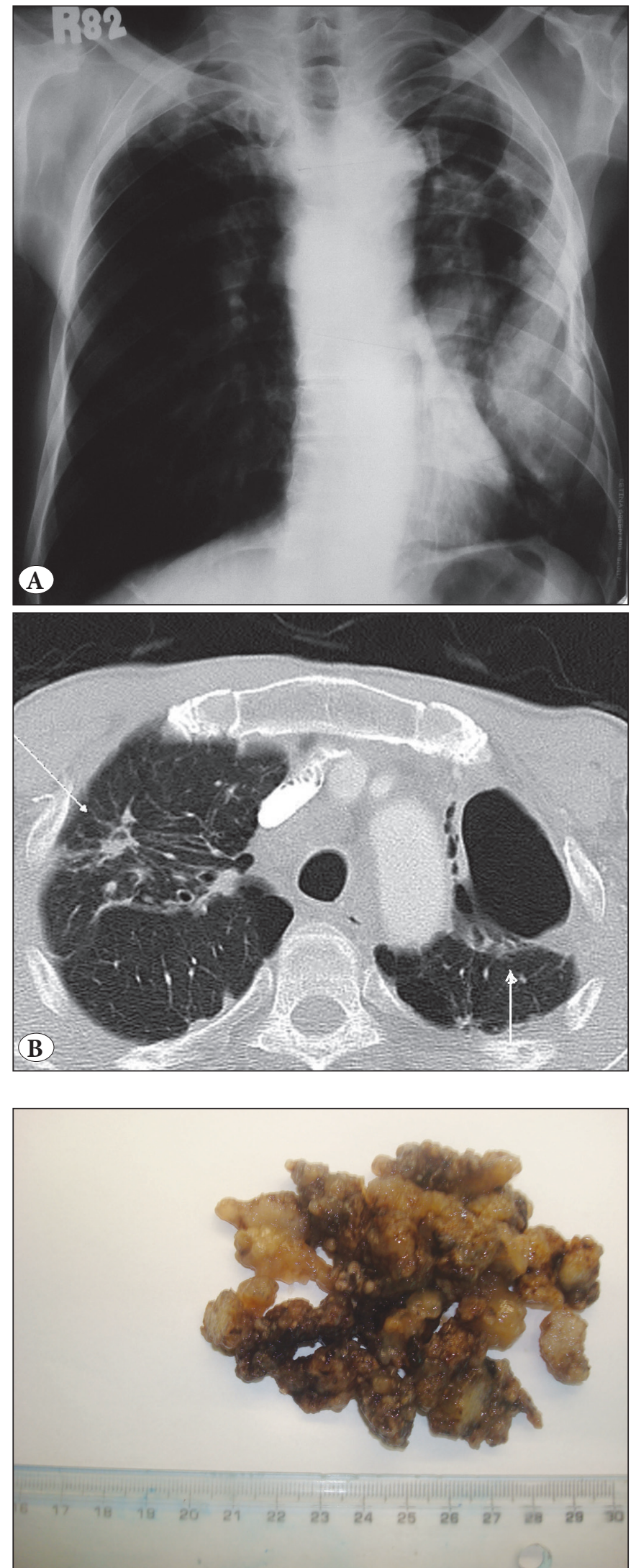

Figure 2: Grossly, the resected material was almost totally gelatinous. revealed no other abnormalities. No adjuvant therapy was given. His postoperative course and two-year follow up was uneventful without any sign of recurrence or metastasis.

\section{DISCUSSION}

The coexistence of tuberculosis and the lung cancer was first described by Bayle in 1810 (5). Since then, there has been several studies on this subject $(3,4)$. The incidence of this coexistency is reported as $2.1-30.2 \%(3,4)$. In these series,

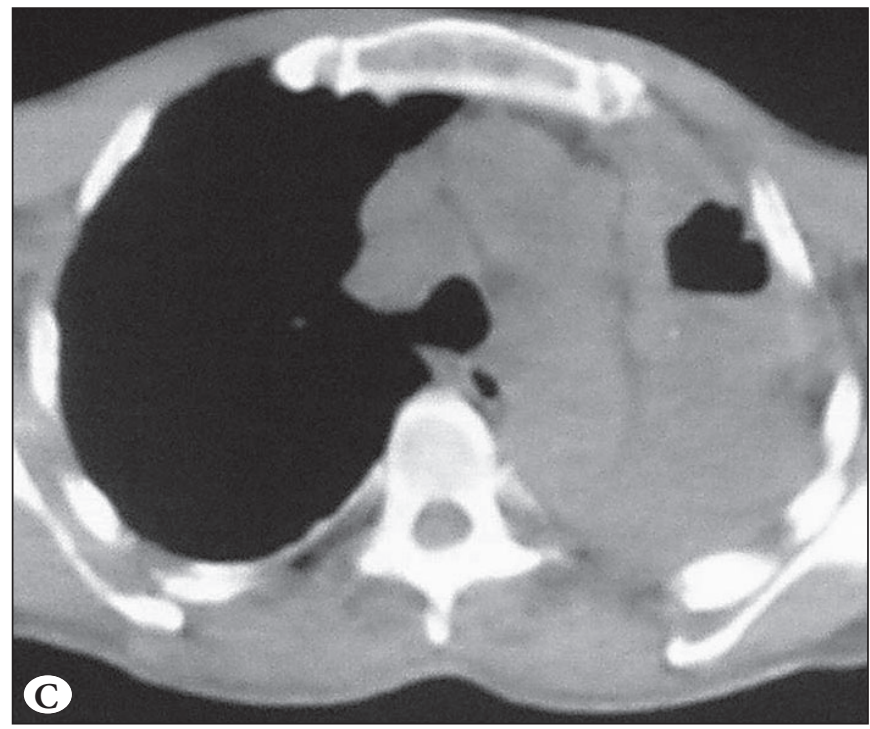

Figure 1: A) X-ray image revealed increased pulmonary opacities and patchy consolidation of the left lung. B,C) CT scan and PETCT fusion images at the same level showed cavitary lesions in the left lung. In figure $1 \mathrm{~b}$, traction bronchiectasis (arrows) and pleural and parenchymal fibrotic changes, highly suggestive for tuberculosis sequela in both lungs. In figure $1 c$, there is a cavitary mass lesion with air-fluid level in the left lung.

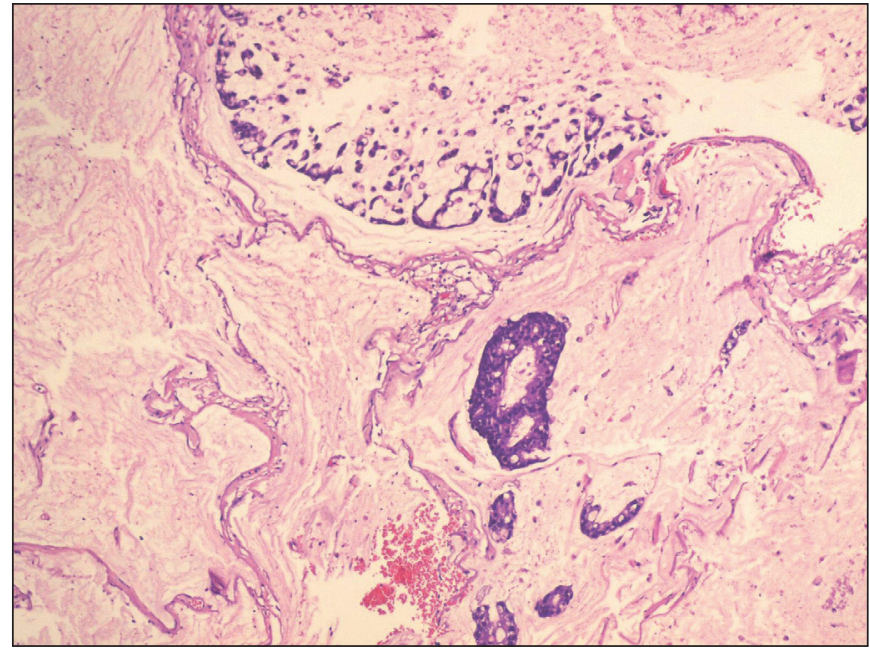

Figure 3: Large mucin pools destroying alveolar septae and neoplastic cell clusters within them. 

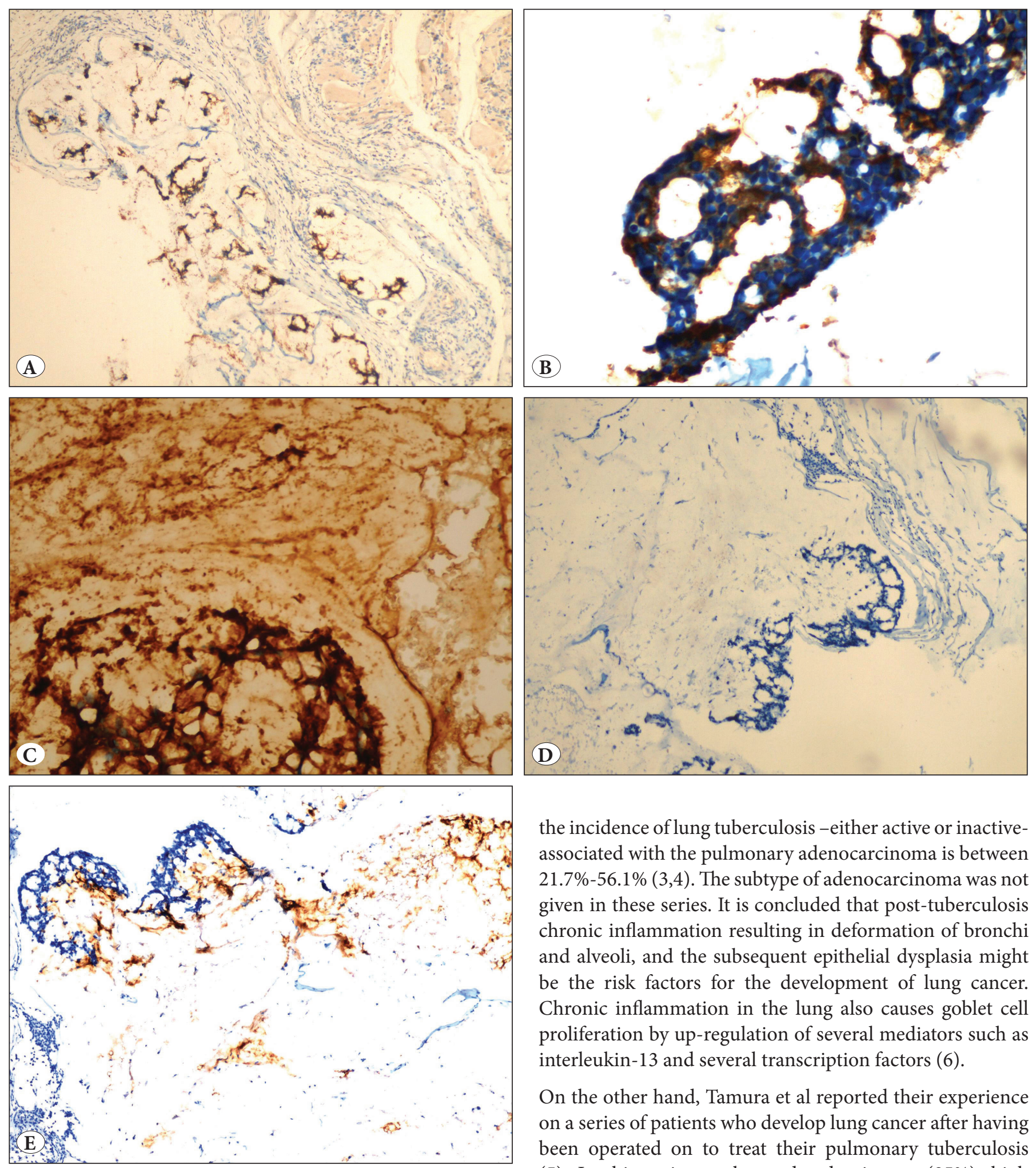

Figure 4: Neoplastic cells were positive for A) CK20, B) MUC2, C) CEA; D) and the tumor was negative for CDX2 E) large mucin pools were positive for MUC5AC.

the incidence of lung tuberculosis - either active or inactiveassociated with the pulmonary adenocarcinoma is between $21.7 \%-56.1 \%(3,4)$. The subtype of adenocarcinoma was not given in these series. It is concluded that post-tuberculosis chronic inflammation resulting in deformation of bronchi and alveoli, and the subsequent epithelial dysplasia might be the risk factors for the development of lung cancer. Chronic inflammation in the lung also causes goblet cell proliferation by up-regulation of several mediators such as interleukin-13 and several transcription factors (6).

On the other hand, Tamura et al reported their experience on a series of patients who develop lung cancer after having been operated on to treat their pulmonary tuberculosis (5). In this series, male gender dominance (85\%), high rate of smoking habbit among them and finally, high rate of having long interval ( $\geq 21$ years) between the time of thoracotomy and the lung cancer development in these patients was reported as significant (5). Our patient is a 
sixty-year-old, a formerly heavy smoker man. This is an interesting case because radiologically, the patient had signs of tuberculosis sequela in both lungs and also had a tumor developed at the area of cavernomyoplasty which was done for the treatment of tuberculosis twenty years back. In this context, we focus on the carcinogenesis triggered by the cavernomyoplasty operation. It is possible that long term deposition of carcinogens due to lymphostasis at the operation site and also post-tuberculosis changes causing destruction of bronchi and alveoli might have initiated the malignant process. We think that chronic inflammation might probably induced excessive goblet cell proliferation and subsequently initiated this malignancy of mucinous type.

According to the International Association for The Study of Lung Cancer/American Thoracic Society/European Respiratory Society Classification suggested in 2011, mucinous (colloid) adenocarcinoma is suggested as a rare low grade variant of invasive adenocarcinoma of the lung composed of either tall-columnar goblet cells, signetring cells or both $(1,2)$. The presence of abundant mucin pools destructing the alveolar septae and having neoplastic cells within these mucin pools is typical (2). Metastatic tumor from a primary mucinous adenocarcinoma of the alimentary tract, ovary, or pancreas to the lungs should be ruled out by performing a careful systemic investigation. Immunohistochemically, mucinous adenocarcinoma of goblet cell type is usually positive for CK20 (2). Although less intense and diffuse than in conventional lung adenocarcinoma, CK7 and TTF-1 positivity may be useful for confirming the pulmonary origin (2). In our case, large mucin pools with neoplastic cells within were destructing the alveolar septae in all areas. The tumor cells were negative for CK7, TTF-1, CDX2 and positive for CK20, CEA and MUC2. The large mucinous matrix stained positively for
MUC5AC. Hence, the immunostains were not useful to rule out any metastatic lung disease. Intense clinical, imaging and laboratory tests were employed to decide the origin of the tumor as being the lung.

In conclusions; primary mucinous (colloid) adenocarcinoma is a rare type of low grade malignancy of the lung. Though rare, its arising in cavernomyoplasty site in patients with history of lung tuberculosis should be kept in mind. Differential diagnosis with metastatic colorectal adenocarcinoma is also challenging and requires appropriate clinical investigation especially when immunohistochemical findings are deceiving.

\section{REFERENCES}

1. Travis WD, Brambilla E, Noguchi M, Nicholson AG, Geisinger K, Yatabe Y, Powell CA, Beer D, Riely G, Garg K, Austin JH, Rusch VW, Hirsch FR, Jett J, Yang PC, Gould M; American Thoracic Society. International Association for the Study of Lung Cancer/American Thoracic Society/European Respiratory Society. International multidisciplinary classification of lung adenocarcinoma: Executive summary. Proc Am Thorac Soc. 2011;8:381-5.

2. Rossi G, Murer B, Cavazza A, Losi L, Natali P, Marchini A, Capitanio G, Brambilla E. Primary mucinous (so-called colloid) carcinomas of the lung. A clinicopathologic and immunohistochemical study with special reference to CDX-2 homeobox gene and MUC expression. Am J Surg Pathol. 2004;28:442-52.

3. Cicenas S, Vencevičius V. Lung cancer in patients with tuberculosis. World J Surg Oncol. 2007;5:22.

4. Dacosta NA, Kinare SG. Association of lung carcinoma and tuberculosis. J Postgrad Med. 1991;37:185.

5. Tamura A, Hebisawa A, Hayashi K, Sagara Y, Kawabe Y, Nagayama N, Machida K, Fukushima K, Yotsumoto H, Mori M. Lung cancer in patients who had received thoracoplasty for pulmonary tuberculosis. Jpn J Clin Oncol. 1999;29:541-5.

6. Turner J, Jones CE. Regulation of mucin expression in respiratory diseases. Biochem Soc Trans. 2009;37:877-81. 